\title{
Evidence of climate shift for temperature and precipitation extremes across Gansu Province in China
}

\author{
Dong $\mathrm{An}^{1} \cdot$ Yiheng $\mathrm{Du}^{1}{ }^{1} \cdot$ Ronny Berndtsson ${ }^{1,2} \cdot$ Zuirong Niu $^{3} \cdot$ Linus Zhang ${ }^{1} \cdot$ Feifei Yuan ${ }^{4}$
}

Received: 16 June 2018 / Accepted: 3 November 2019 /Published online: 26 November 2019

(C) The Author(s) 2019

\begin{abstract}
Temperature and precipitation extremes are the dominant causes of natural disasters. In this study, seven indices of extreme temperature and precipitation events in Gansu Province, China, were analysed for the period 1961-2017. An abrupt climate shift was recorded during 1980-1981. Thus, the study period was divided into a preshift (before the climate shift) period 1961-1980 and an aftshift (after the climate shift) period 1981-2017. Comparison of mean extreme indices for preshift and aftshift periods was performed for the purpose of exploring possible increasing/decreasing patterns. Generalized extreme value (GEV) distribution was applied spatially to fit the extreme indices with return periods up to 100 years for preshift/aftshift periods. Singular value decomposition (SVD) was adopted to investigate possible correlation between the extreme climate events and indices of largescale atmospheric circulation. The results indicate that changes in mean and return levels between the preshift and aftshift periods vary significantly in time and space for different extreme indices. Increase in extreme temperature regarding magnitude and frequency for the aftshift period as compared with the preshift period suggests a change to a warmer and more extreme climate during recent years. Changes in precipitation extremes were different in southern and northern parts of Gansu. The precipitation extremes in the north have increased that can result in more serious floods and droughts in the future. SVD analyses revealed a complex pattern of correlation between climate extremes and indices of large-scale atmospheric circulation. Strengthening of westerlies and weakening of the south summer monsoon contribute to the complex changing patterns of precipitation extremes. Results in this study will contribute to disaster risk prevention and better water management in this area.
\end{abstract}

Keywords Temperature extremes $\cdot$ Precipitation extremes $\cdot$ Frequency analysis $\cdot$ Teleconnection patterns $\cdot$ Gansu Province

\section{Introduction}

Extreme climate events are of great concern for the public, government and the academic community due to their disastrous environmental and socio-economic consequences. The occurrence of extreme events and their potentially severe impacts have been emphasized due to climate change effects (Karl and Easterling 1999; Allan and Soden 2008; Casanueva et al. 2014;

Yiheng Du

yiheng.du@tvrl.lth.se

1 Department of Water Resources Engineering, Lund University, Lund, Sweden

2 Center for Middle Eastern Studies, Lund University, Lund, Sweden

3 Gansu Agricultural University, Lanzhou, China

4 State Key Laboratory of Hydrology, Water Resources, and Hydraulic Engineering, Hohai University, Nanjing, China
Gao and Xie 2016). Especially, arid and semiarid regions are often considered more vulnerable to climate change (Wen et al. 2017) due to large spatiotemporal variation and sensitive ecological systems (Cudennec et al. 2007; Guan et al. 2018). Northwestern China is one of the most arid areas in East Asia. Many studies have shown that Northwestern China is more sensitive to extreme climate events as compared with other areas. It has been found that temperature and precipitation in Northwestern China have experienced a sharp increase during the past 50 years (Chen et al. 2015). Also, the ratio of extreme to mean precipitation has increased markedly (Zhai et al. 2005; Feng et al. 2007; Zhou et al. 2016). The results indicate a severe future climate situation in Northwestern China with larger variability for both temperature and precipitation.

In the arid and semiarid areas of Northwestern China, Gansu Province $\left(32^{\circ} 31^{\prime}-42^{\circ} 57^{\prime} \mathrm{N}\right.$ and $\left.92^{\circ} 13^{\prime}-108^{\circ} 46^{\prime} \mathrm{E}\right)$ is of special importance due to its economic and ecological conditions. Located in the north-west inland region of China, Gansu Province is an agricultural province with a primary 
production of grain and cash crops. However, the climatic condition is not advantageous for the development of agriculture. On the contrary, Gansu Province suffers from either severe water shortages and droughts or floods and mudslides. Several major floods and droughts have occurred during recent years causing devastating socioeconomic damages. During recent decades, the environment has become more vulnerable to extreme weather due to an increasing population and rapid urbanization (Cheng et al. 2017; Wang et al. 2017b). Besides, being an important national ecological barrier against sand storms, Gansu Province also constitutes an important water conservation area for both Yellow River and Yangtze River in China. Meanwhile, the landforms of Gansu Province are complex and diverse, including mountains, plateaus, deserts and Gobi landscapes, which are especially sensitive to extreme climate change (Diaz et al. 2003). To summarize, for a better water management, disaster control and ecological sustainability, it is important to discover trends and potential physical mechanisms of meteorological extremes such as precipitation and temperature.

Several previous studies have investigated precipitation and temperature variation for the Gansu Province. Jia (2016) studied extreme temperature indices in Qilian Mountain and Hexi Corridor in northern part of Gansu and found that extreme temperature had a significantly increasing trend during 1960-2013. Li et al. (2013) compared the temperature and precipitation changes for three different landscape types, mountain, oasis and desert areas in Northwestern China and revealed a faster increase for both temperature and precipitation in desert areas. Li and Wang (2017) found a decreasing trend for both extreme precipitation and wet spells in south-eastern Gansu, whereas the trend in northwestern Gansu is an increase in precipitation. Wen et al. (2017) analyzed the spatiotemporal variation of temperature and precipitation extremes in Gansu and found a significantly warming trend especially for high latitudes but no trend for precipitation. Meanwhile, in all above studies, only the magnitude characteristics of extreme indices were investigated, and changes in frequency have not yet been thoroughly analyzed.

All above studies on extreme temperature and precipitation in Gansu analyzed the entire study period as a whole (usually 1960s to 2010s). However, it has been found that China has experienced a significant decadal change in the late 1970s, which was related to the abrupt change in the large-scale boreal winter circulation pattern over the North Pacific (Graham 1994). Hu et al. (2004) found a significant increase of Northern Hemisphere sea surface temperature in boreal summer and winter since 1980 , and available potential energy has increased after 1980, which has significantly affected the climate of China. Gong and Ho (2002) found a significant shift of summer rainfall in eastern China from about 1979. Tu et al. (2010) noticed that many precipitation indices in China exhibit a climatic jump at about 1980. In particular, the widely concerned drying process in North China was essentially formed by this climatic jump, indicating a weakening or southward retreating process of the East Asian summer monsoon. Thus, the climate shift in the late 1970s should be considered when analysing regimes of climate extremes. However, this has rarely been taken into account in previous studies focusing on extremes in Gansu Province, which might be the reason why no general consensus regarding the spatial pattern of precipitation extremes has been obtained. Therefore, the spatiotemporal characteristics of temperature and precipitation extremes over Gansu Province need to be examined comprehensively by considering the rainfall shift in the late 1970s to contribute useful information for long-term risk management. In this study, we selected 1980 as a temporal shift point. Accordingly, the periods 1961-1980 and 1981-2017 were considered as preshift (before the shift) and aftshift (after the shift) period, respectively.

To reveal the possible mechanisms for the variation of temperature and precipitation extremes, correlation with global atmospheric circulation is considered in this study as numerous studies have shown that global atmospheric circulation has strong influence on the variability of localized hydrological response at different spatial and temporal scales (Redmond and Koch 1991; Yuan et al. 2008; Casanueva et al. 2014; Xiao et al. 2015; Yuan et al. 2016a). Improving the knowledge on relationships between precipitation and temperature extremes and global teleconnection patterns could help to project the frequency and severity of future climatic extremes in Gansu Province.

In view of the above, the objective of this study was to investigate the variation of temperature and precipitation extremes considering the climate shift in the late 1970s by comparing the magnitude and frequency before and after the shift. To explore the physical mechanisms of variation, links between extremes and global teleconnection patterns were investigated. It is important to quantify the above potential variation in extreme climate events for Gansu Province and to establish global-scale links to improve the physical understanding of variability of extremes with major implications for water resources management to mitigate risks and potentially devastating hydrological responses.

\section{Data and methods}

\subsection{Study area and data}

Located in the inner land of Northwestern China (Fig. 1b), Gansu Province is characterized by a combination of cold desert climate (Bwk), cold semiarid climate (Bsk), temperate continental climate (Dwb) and cool continental climate (Bwc), based on Köppen Geiger climate classification system (Peel et al. 2007). It covers four zones (arid Northwest China, 


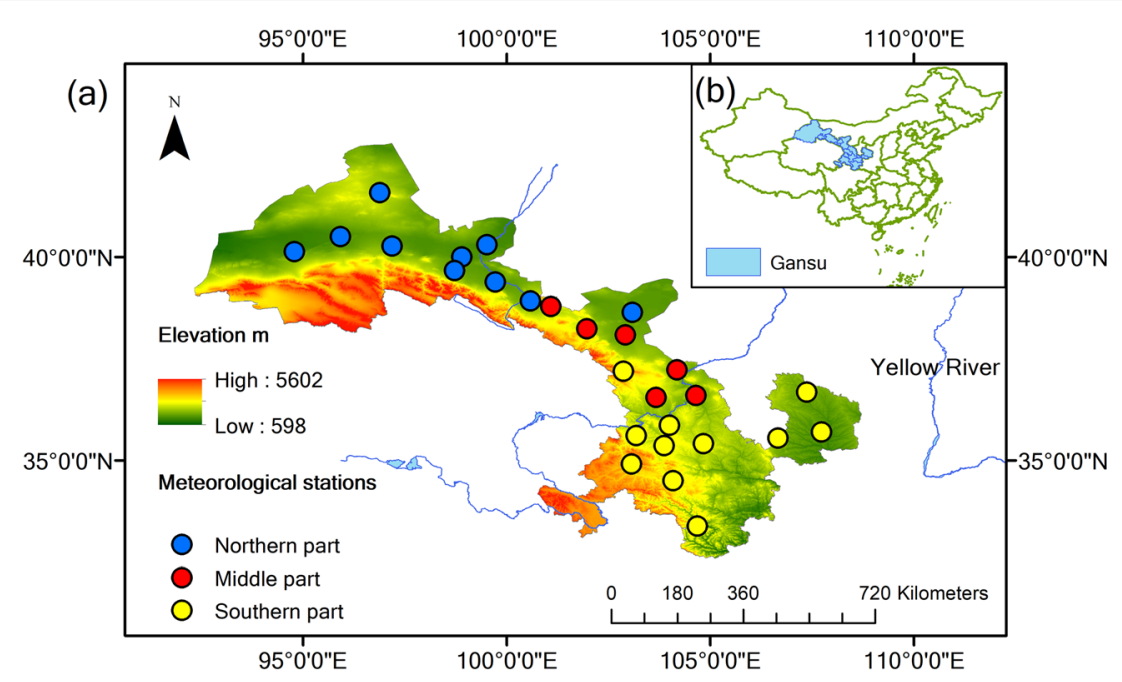

Fig. 1 General information of Gansu Province: a topography, river network ,meteorological stations and sub-regions; $\mathbf{b}$ location in China

monsoon north China, monsoon south China and Tibetan Plateau). The terrain is inclined from south-west to north-east, with an elevation ranging from 598 to $5602 \mathrm{~m}$ (Figure 1a).

a), based on The Shuttle Radar Topography Mission (SRTM) 90-m digital elevation data from the Consortium for Spatial Information (CGIAR-CSI). Qilian Mountain lies along the south-west side of Gansu, and there are three deserts that cover part of Gansu or lie nearby. The annual total precipitation ranges from 40 to $800 \mathrm{~mm}$ with a drying gradient from south-east to north-west (Wang et al. 2017a). About $70 \%$ of annual precipitation in this area falls during the summer season (June-September). Annual mean temperature ranges from 0 to $15{ }^{\circ} \mathrm{C}$, increasing from Qilian mountainous area northward and southward. The variability in temperature and precipitation is attributed to combined effects of the monsoon system and topography. Daily temperature and precipitation data collected from 27 meteorological stations (Fig. 1a) were obtained from the China Meteorological Administration (CMA, http://data.cma.gov.cn) for the period 1961 to 2017. The data quality has previously been evaluated by the CMA with repeated verification and quality controls. All 27 stations have continuous gauged data series with no missing values for the study period. Thus, this qualified to perform the present analysis. A simple clustering by principle component analysis of the 27 stations was carried out based on mean annual temperature and precipitation, yielding three main sub-areas of the Gansu Province (Fig. 1a). The results in this study are discussed for each of these sub-areas named northern, middle and southern part.

To describe modes of atmospheric circulation, this study considered four climate indices influencing climate variability over China and especially northern China: North Atlantic Oscillation (NAO), Southern Oscillation Index (SOI), East Atlantic/West Russia Pattern (EA/WR) and Pacific Decadal Oscillation (PDO). Monthly climate indices were obtained from the
National Oceanic and Atmospheric Administration of USA (NOAA), from the website at https://www.cpc.ncep.noaa.gov/ data/ and https://www.ncdc.noaa.gov/teleconnections/. Detailed explanation for each teleconnection pattern is given by Washington et al. (2000) and Barnston and Livezey (1987).

The study period in this paper is 1961-2017, with a 'preshift period' referring to 1961-1980 and an 'aftshift period' referring to 1981-2017. Comparison of different climate variables is conducted between preshift and aftshift periods, and the differences are denoted as $\Delta_{\text {aft-pre. }}$

\subsection{Methods}

\subsubsection{Index calculations}

The RClimDex 1.1 software developed by Climate Research Branch of Meteorological Service of Canada (Zhang and Yang 2004) was used in this study. Seven climatic extreme indices were selected from the list established by the WMO Commission for Climatology (Karl et al. 1999; Peterson et al. 2001) as described in Table 1. In order to identify errors during the analyses and avoid use of inconsistent data, data quality control was performed in the RClimDex software by detecting and replacing all missing and unreasonable values into an internal format that the software recognizes as not available (NA).

Table 1 shows temperature and precipitation indices computed from daily temperature and precipitation time series. The used indices were chosen primarily for assessment of a changing regional climate. Considering the potential influence on agricultural conditions in Gansu, TXx, TNn and GSL were selected to quantify magnitude and duration of extreme temperature. R95P, SDII, CDD and CWD were selected as representatives of precipitation percentiles, intensity and persistence. 
Table 1 Precipitation extreme indices used in this study

\begin{tabular}{lll}
\hline & Description & Unit \\
\hline $\begin{array}{l}\text { T extremes } \\
\text { TXx }\end{array}$ & Annual maximum of daily maximum temperature & \\
TNn & Annual minimum of daily minimum temperature & ${ }^{\circ} \mathrm{C}$ \\
GSL & Growing season length, annual (Jan. 1 to Dec. 31 ) count between first span & ${ }^{\circ} \mathrm{C}$ \\
& $\quad$ of at least 6 days with TG $>5{ }^{\circ} \mathrm{C}$ and first span after July 1 & day \\
of 6 days with $\mathrm{TG}<5{ }^{\circ} \mathrm{C}$ & \\
P extremes & Annual total precipitation when daily precipitation $>95$ th percentile & \\
R95p & Annual total precipitation divided by the number of wet days when $\mathrm{RR} \geq 1 \mathrm{~mm}$ & $\mathrm{~mm} /$ day \\
SDII & Maximum number of consecutive dry days when $\mathrm{RR}<1 \mathrm{~mm}$ & day \\
$\mathrm{CWD}$ & Maximum number of consecutive wet days when $\mathrm{RR} \geq 1 \mathrm{~mm}$ & day \\
\hline
\end{tabular}

RR denotes daily precipitation; TG denotes daily mean temperature.

\subsubsection{Generalized extreme value distribution}

The generalized extreme value (GEV) distribution was developed by Jenkinson (1969), and the cumulative distribution function is defined using the standardized variable $\varsigma=(x$ $-\mu) / \sigma$,

$F(\varsigma ; \xi)=\left\{\begin{array}{cc}\exp \left(-(1+\xi \varsigma)^{-\frac{1}{\xi}}\right) & \xi \neq 0 \\ \exp (-\exp (-\varsigma) & \xi=0\end{array}\right.$

where $\mu \in R$ is a location parameter, $\xi \in R$ is a shape parameter, and $\sigma>0$ is a scale parameter. For $\xi>0$, the expression is valid for $\varsigma>-1 / \xi$, while for $\xi<0$, the expression is valid for $\varsigma<-1$ $/ \xi$.

In probability theory, the GEV distribution is a family of continuous probability distributions developed within extreme value theory to combine the Gumbel, Fréchet and Weibull families, which correspond to the case $\xi=0, \xi>0$ and $\xi<$ 0 , respectively. Parameters are estimated through automated techniques at a significance level of 0.05 , which is maximum likelihood in this study.

The $n$-year return period $y_{n}$ is defined by setting Eq. (1) equal to $1-\frac{1}{n}$. Solution to the resulting equation is $y_{n}$. The GEV distribution for each extreme index was computed, and return periods in preshift/aftshift for 20,50 and 100 years were compared to investigate whether the climate in Gansu has become more extreme after the climate shift.

\subsubsection{Relationship between extremes and global circulation patterns}

Multivariate analysis known as SVD was applied to discover relationships between temperature and precipitation extremes and global circulation patterns. SVD utilizes the crosscovariance matrix between fields of two datasets and isolates the combinations of variables within the fields that tend to be linearly related to one another by maximizing the covariance between them. A detailed description of the statistical procedure is discussed by Bretherton et al. (1992) and Wallace et al. (1992). In this study, SVD was performed using the cross-covariance matrix of the $s(t, x)$ matrix of $x$ climatic indices (NAO, SOI, PDO and EAWR) at $t$ years and the $z(t, y)$ matrix composed by temperature and precipitation extremes at $t$ years. The SVD of $s(t, x)$ and $z(t, y)$ yields two matrices of singular vectors and one set of singular values for each mode. A singular vector pair describes spatial patterns for each field that has overall covariance given by the corresponding singular value. Heterogeneous correlation maps of the left and right fields in $s(t, x)$ and $z(t, y)$ from SVD show correlation coefficients between one field and the singular vector of the other field (Uvo et al. 1998; Yuan et al. 2016a). In our case, the patterns shown by the heterogeneous correlation maps for the $k$ th SVD mode indicate how well the pattern of the temperature and precipitation extremes relate to the $k$ th singular vector of climate indices. The correlation coefficients are good indication of strength of the relationship between the two fields.

\section{Results and discussion}

\subsection{Spatial variation of extreme indices before/after the climate shift}

The spatial pattern of temperature extreme indices (TXx, TNn and GSL) in Gansu Province is shown in Fig. 2. Figure 2a-c shows mean temperature extreme indices, while Fig. $2 \mathrm{~d}-\mathrm{f}$ shows the difference between the aftshift and preshift period for each index. TXx varies over the area but is in most parts higher than $30{ }^{\circ} \mathrm{C}$, in general with higher values in the northwestern areas and decreasing towards the south-east, ranging from 23.1 to $38.7^{\circ} \mathrm{C}$ (Fig. 2a). This distribution is mainly due to the topography and vegetation diversity. The highest TXx occurs at the extreme north-west, located in the desert area, and lowest TXx occurs in the middle area, located at a high 
(a) TXX

${ }^{\circ} \mathrm{C}$

- $(20.0,25.0]$

- $(25.0,30.0]$

$(30.0,35.0]$

$(35.0,40.0]$

(b) $\mathrm{TNn}$

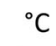

$(-30.0,-25.0]$

$(-25.0,-20.0]$

$(-20.0,-15.0]$

- $(-15.0,-10.0$ ]

- $(-10.0,-5.0]$

- $(-5.0,0.0]$
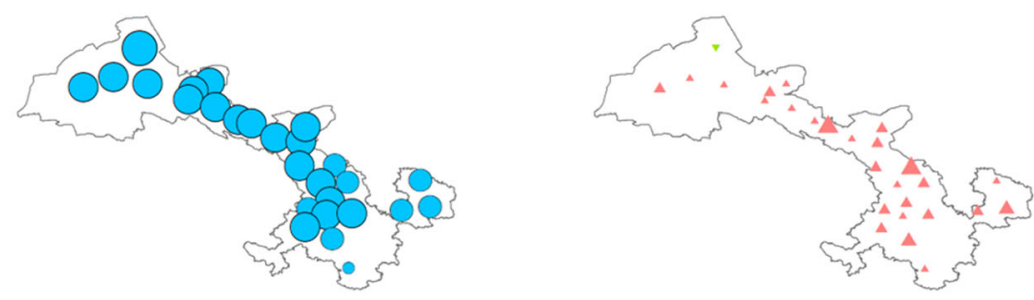

(e) $\Delta_{\text {aft-pre }} T N n$

${ }^{\circ} \mathrm{C}$

$(-1.0,0.0]$

$(0.0,1.0]$

$(1.0,2.0]$

$(2.0,3.0]$

$(3.0,4.0]$ (c) GSL

day

- $\quad(140.0,150.0$

$-(150.0,200.0]$
$-\quad(200.0,250.0]$

- $(250.0,300.0]$

$(300.0,350.0]$
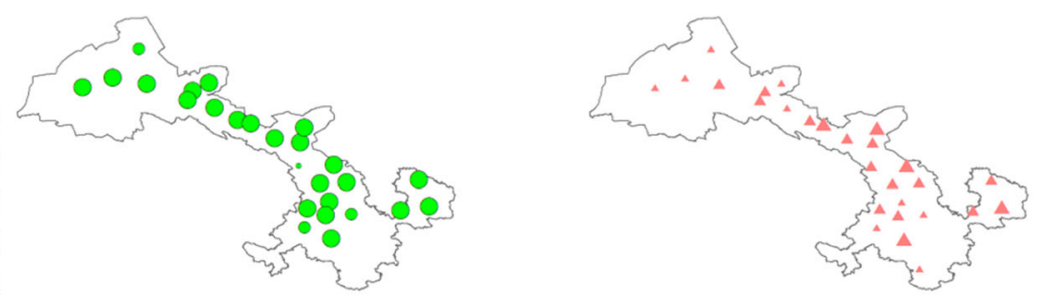

(f) $\Delta_{\text {aft-pre }} G S L$

day

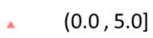

$\triangle \quad(5.0,10.0]$

$\triangle \quad(10.0,15.0]$

$\Delta \quad(15.0,20.0]$

Fig. 2 Spatial distribution of temperature extreme indices in Gansu during 1961-2017 and difference between preshift/aftshift period: a-c mean of TXx, TNn and GSL for the entire study period and $\mathbf{d}-\mathbf{f} \Delta_{\text {aft-pre }}$ TXx, $\Delta_{\text {aft-pre }}$ TNn and $\Delta_{\text {aft-preGSL }}$

elevation above $3000 \mathrm{~m}$. TNn in most parts of Gansu is lower than $-20^{\circ} \mathrm{C}$, and highest values are found in the southern part, belonging to temperate continental climate (Fig. 2b). By comparing the spatial distribution of TXx and TNn, higher TXX and lower TNn occur in the northern and middle Gansu, while lower TXX and higher TNn occur in southern Gansu, indicating different daily temperature variation characteristics. GSL in most part of Gansu is between 200 and 250 days (Fig. 2c), which gives 6 to 8 months of growing season. Comparing the difference between aftshift and preshift period, all 27 stations show an increase of TXx and GSL in the aftshift period compared with the preshift period, ranging from 0.2 to $1.8^{\circ} \mathrm{C}$ (Fig. $2 \mathrm{~d}$ ) and 0.10 to 12.0 days (Fig. 2f). For TNn, 26 stations showed an increase ranging from 0.2 to $3.0^{\circ} \mathrm{C}$ (Fig. 2e) while one station located in the very north showed a decrease of -0.6 ${ }^{\circ} \mathrm{C}$. The results indicate that in the aftshift period, temperature extremes in most parts of Gansu had higher TXx, higher TNn and longer GSL. Since both TXx and TNn showed higher values in the aftshift period, the difference between TXx and TNn should be examined. The difference in extreme temperature $(\mathrm{TXx}-\mathrm{TNn})$ in preshift/aftshift period was computed and compared (Fig. 3). Most stations showed negative values, which means TXx-TNn in aftshift period was smaller than for the preshift period, giving a small variation range of temperature extremes in the aftshift period.

Spatial patterns of precipitation extreme indices (R95P, SDII, CDD and CWD) in Gansu are shown in Fig. 4. Figure 4a-d shows mean of precipitation extreme indices, while Fig. $4 \mathrm{e}-\mathrm{h}$ shows the difference between aftshift and preshift period for each index. Clear variation from north-west to south-east is revealed in the spatial patterns: R95P varied from 7.2 to $362.8 \mathrm{~mm}$; SDII changed from 3.8 to $8.4 \mathrm{~mm} / \mathrm{day}$; CDD decreased from 6.0 to 1.8 days; and CWD varied with average 3.8 days from minimum 1.8 days to maximum 6.0 days. The spatial variation is a function of topography and eastern monsoon distribution. Since Qilian Mountain lies along the south-western side of Gansu and functions as a natural barrier for east winds bringing moisture from Pacific Ocean and forces them to move along the mountain. During the process, moisture decreases as the wind moves further into the north-west.

Comparing the difference between aftshift and preshift periods, a similar spatial distribution can be seen for R95P and SDII (Fig. 4e, f). The southern part shows a decrease and other parts mainly an increase for the aftshift period. The results indicate that in the southern most humid area of Gansu, extreme precipitation tended to be less extreme during the 
Fig. 3 Difference Txx-Tnn between preshift and aftshift period: $\Delta_{\text {aft-pre }}($ Txx-Tnn $)$

$$
\begin{array}{ll}
\nabla & (-3.0,-2.5] \\
\nabla & (-2.5,-2.0] \\
\nabla & (-2.0,-1.5] \\
\nabla & (-1.5,-1.0] \\
\nabla & (-1.0,-0.5] \\
\nabla & (-0.5,0.0] \\
\Delta & (0.0,0.5] \\
\Delta \quad(0.5,1.0] \\
\Delta \quad(1.0,1.5] \\
\Delta \quad(1.5,2.0] \\
\Delta \quad(2.0,2.5]
\end{array}
$$

Unit: ${ }^{\circ} \mathrm{C}$ preshift period, while in other areas, the intensity of extreme precipitation had an increasing tendency. Regarding the difference between aftshift/preshift period for CDD (Fig. 4g), most areas show negative values, which means that in the aftshift period, the length of consecutive dry days decreased, indicating more frequent precipitation events. For CWD (Fig.
Fig. 4 Spatial distribution of precipitation extreme indices in Gansu during 1961-2017 and difference between preshift/ aftshift period: a-d mean of R95P, SDII, CDD and CWD for the entire study period and $\mathbf{e}-\mathbf{h}$ $\Delta_{\text {aft-pre }}$ R9P, $\Delta_{\text {aft-pre }}$ SDII, $\Delta_{\text {aft- }}$ pre $\mathrm{CDD}$ and $\Delta_{\text {aft-pre }} \mathrm{CWD}$ (a) R95P mm

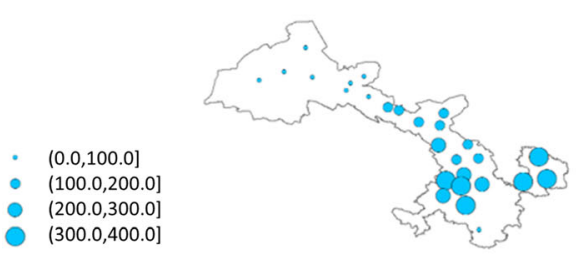

(b) SDII mm/day

$(3.0,5.0]$

- $(5.0,7.0]$

$(7.0,9.0]$

(c) CDD day

$(50.0,100.0]$

$(100.0,150.0]$

(150.0, 200.0]

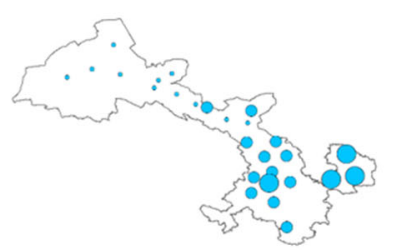

(f) $\Delta_{\text {aft-pre }}$ SDII mm/day

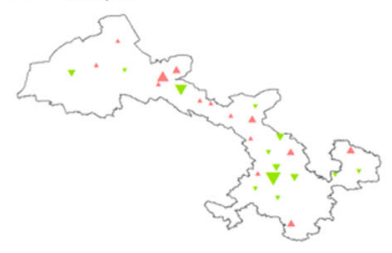

$\begin{array}{ll}\nabla & (-0.8,-0.6] \\ \nabla \quad & (-0.6,-0.4] \\ * \quad & (-0.4,-0.2] \\ & (-0.2,0.0] \\ & (0.0,0.2] \\ * \quad(0.2,0.4] \\ & (0.4,0.6]\end{array}$

(g) $\Delta_{\text {aft-pre }}$ CDD day

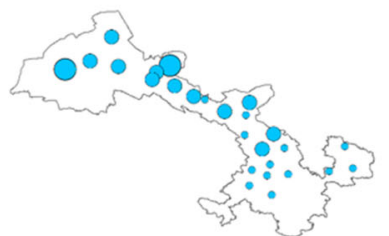

(d) CWD day

- $(0.0,2.0]$

- $(2.0,4.0]$

- $(4.0,6.0]$

- $(6.0,8.0]$ (e) $\Delta_{\text {aft-pre }} R 95 \mathrm{P}$ mm

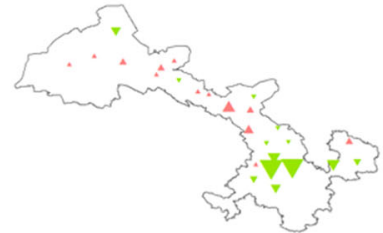

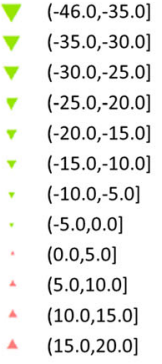

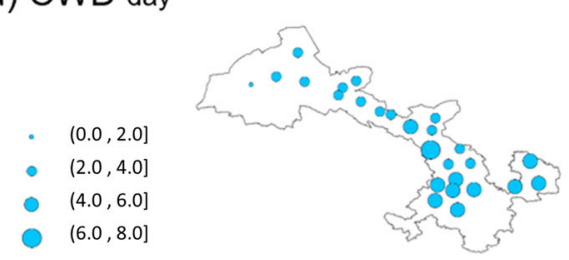

(h) $\Delta_{\text {aft-pre }} C W D$ day

$\begin{array}{ll}\nabla & (-1.5,-1.25] \\ \nabla & (-1.25,-1.0] \\ \nabla & (-1.0,-0.75] \\ \nabla & (-0.75,0.5] \\ \nabla & (-0.5,-0.25] \\ > & (-0.25,0.0] \\ \Delta & (0.0,0.25] \\ \Delta & (0.25,0.5]\end{array}$ 
4h), the northern areas display mainly positive values while the southern parts mainly negative values. This suggests that in the aftshift period, the length of consecutive wet days increased in the north and decreased in the south. To summarize, in the southern part of Gansu, decreasing R95P, SDII, CDD and CWD occurred, which indicates less extreme precipitation pattern in this area with lower extremes, lower rainfall intensity and shorter consecutive rainy days. In the northern Gansu, precipitation showed increase for R95P, SDII and CWD and decrease for CDD, which suggests strengthening of precipitation extremes with higher extremes, higher rainfall intensity and longer consecutive rainy days. These results confirm previous studies using trend analyses. Li and Wang (2017) found decreasing trend for extreme precipitation in south-eastern Gansu, whereas the trend for north-western Gansu was an increase for precipitation.

\subsection{Frequency changes of extreme indices before/after the climate shift}

Variation in climate extremes was analysed on the basis of return period for 20-100 years. Two time periods 1961-1980 (preshift period) and 1981-2017 (aftshift period) were analysed, respectively. To reveal the frequency variation of each extreme index before and after the climate shift, the difference between return level of aftshift and preshift for $T=20,50$ and 100 years was calculated, and spatial patterns of the difference were derived using inverse distance weighted interpolation as the stations in this study are densely and evenly distributed.

For extreme temperature indices, spatial distribution of differences between preshift/aftshift period ( $T=20,50$ and 100 years) is shown in Fig. 5. For TXx (Fig. 5a), the return levels for aftshift display an increase as compared with the preshift for the entire Gansu Province ( $T=20,50$ and 100 years). The main increasing area is located in the Hexi Corridor in the middle part of Gansu. For TNn (Fig. 5b), the return levels ( $T=20,50$ and 100 years) for the aftshift are larger than those for the preshift, in entire Gansu Province except for one station in the northern part. The maximum increasing magnitude is in the Hexi Corridor area that gradually decreases towards north and south. For GSL (Fig. $5 c$ ), in most parts of Gansu, the return levels for aftshift increased more than those for the preshift ( $T=20,50$ and 100 years), while two stations in the northern part displayed decreasing return levels in the aftshift ( $T=50$ and 100 years). The magnitude of increase in GSL for the aftshift period was more significant in the southern part of Gansu as compared with the north. To conclude, the return levels of extreme temperature in Gansu Province showed increasing trend in the aftshift period that resulted in warmer climate.

For precipitation extremes, a mixed pattern was observed regarding return levels in Gansu at for preshift and aftshift periods. For R95P (Fig. 6a), increasing return levels ( $T=20$, 50 and 100 years) were revealed mainly in the Hexi Corridor (middle part of Gansu) and Longnan area (south-eastern part of Gansu) for aftshift. Other parts of Gansu showed decreasing return levels for the aftshift. The results indicate more extreme precipitation in the Hexi Corridor and Longnan area in recent years that should be taken into consideration as these two areas correspond to important crop production. For SDII (Fig. 6b) and return levels 20, 50 and 100 years, stations dominated by increasing return levels in aftshift are mainly located in the arid north, part of Hexi Corridor in the middle, and the eastern area of the Loess Plateau. These areas covered by desert, loess and agricultural production land are vulnerable to climate change. The CDD (Fig. 6c) and CWD (Fig. 6d) are interpreted in combination with R95P and SDII. In the north part of Gansu, return levels for CDD show an increase for aftshift, while in the same area, CWD shows a decrease $(T=$ 20, 50 and 100 years). This means, longer consecutive dry periods and shorter consecutive wet periods give the north part of Gansu a more intensive precipitation regime in the aftshift period, which corresponds to decreasing R95P and increasing SDII (Fig. 6a, b). For the Hexi Corridor, decreasing return levels for CDD and increasing for CWD indicate a more even precipitation regime ( $T=20,50$ and 100 years), which can be explained by the increasing R95P and decreasing SDII (Fig. $6 \mathrm{a}, \mathrm{b})$. For the Longnan area in the south-east, increase in $\mathrm{CDD}$ and CWD suggests an uncertain pattern of precipitation regime in the aftshift period ( $T=20,50$ and 100 years). The increasing R95P and SDII in this area indicates a more intensive precipitation regime after the climate shift. The results give important information on the frequency of temperature and precipitation extremes in different parts of the Gansu Province, which should be considered during irrigation and drought/flood mitigation for each specific area.

Meanwhile, extrapolation of results from short observation periods to longer return periods results in uncertainty in the GEV estimations (De Michele and Avanzi 2018). This is especially true when using data subsets to assess long return periods. The purpose of using return periods was to compare the distribution of extreme indices between preshift/aftshift periods. In this sense, it is the relative amplitude of difference between the return levels that really matters, rather than the exact values. This, in some sense, leads to more robust results as compared with individual values.

\subsection{Associations between extreme climate and large-scale circulation}

To investigate possible teleconnections between large-scale circulation and extreme temperature and precipitation in Gansu Province, SVD was applied using the cross-variance matrix between temperature and precipitation extremes and climate indices (NAO, SOI, PDO and EAWR) for the period 1961 to 2017. The leading first two modes were used since they captured the most explained variance. Figure 7 presents the 
(a)

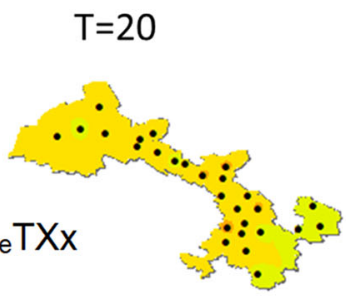

$\Delta_{\text {aft-pre }} T X x$

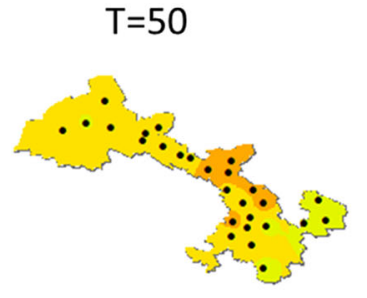

(b)
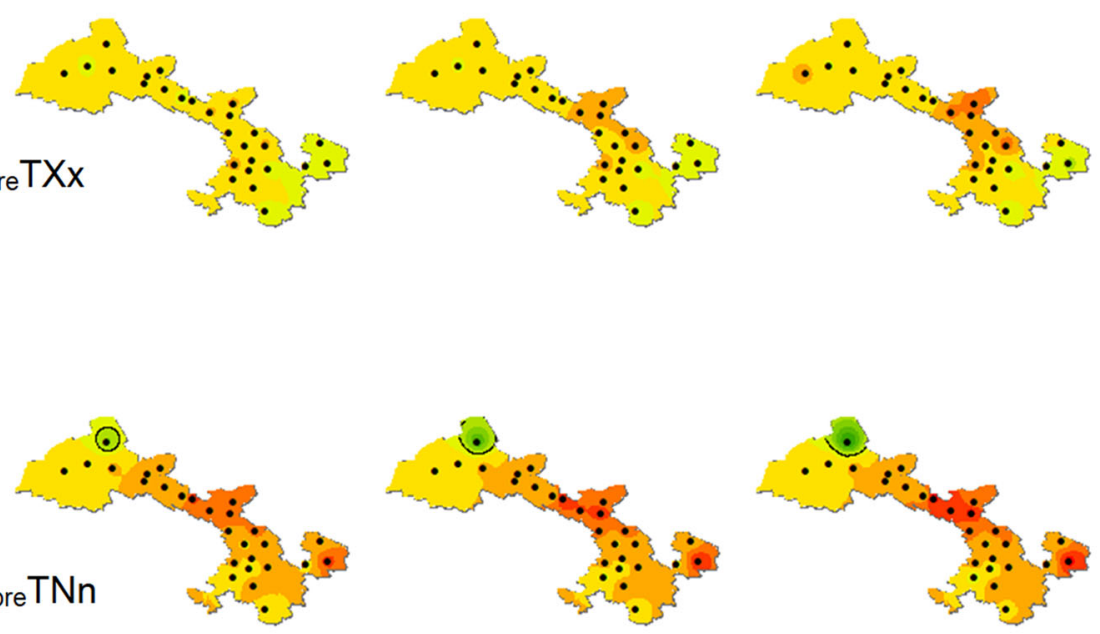

$\mathrm{T}=100$

(c)
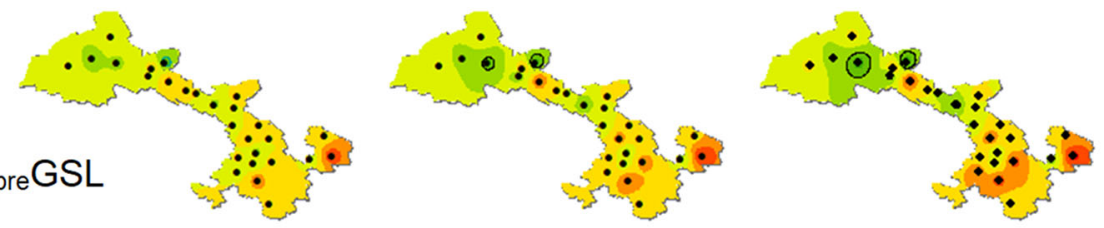

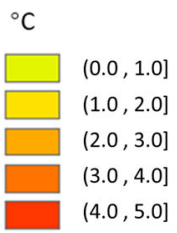

${ }^{\circ} \mathrm{C}$

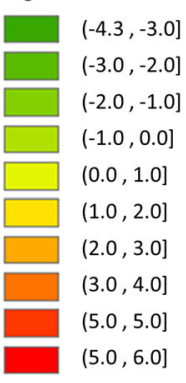

day

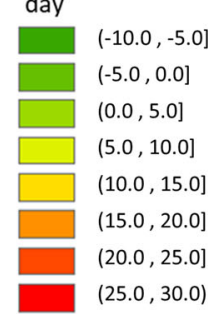

Fig. 5 Spatial distribution of return level difference between aftshift and preshift period for extreme temperature indices: a $\Delta_{\text {aft-pre }}$ TXx, b $\Delta_{\text {aft-pre }}$ TNn

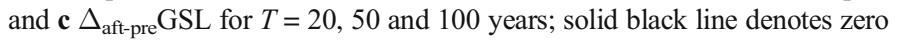

heterogeneous correlation for temperature extremes, and Table 2 presents the corresponding heterogeneous correlation of climate indices for the first and second mode of SVD, only showing significant values $(p<0.05)$. It is noteworthy that all stations for temperature extremes showed significant correlation for the first mode: TXx and GSL showed negative association with NAO, PDO and EAWR and positive association with SOI for the first mode at 0.05 significance level; TNn showed positive association with NAO, PDO and EAWR and negative association with SOI for the first mode. For the second mode, TXx showed significant correlation only at three stations in the northern part and five stations in the middle and southern part: negative correlation with SOI and EAWR and positive correlation with PDO at stations in the north and positive correlation with SOI and EAWR and negative correlation with PDO at stations in the middle and south. TNn presented significant correlations in the southern part for the second mode, mostly consistent association with PDO and inversely associated with NAO and EAWR. For the second mode and GSL, most stations displayed significant positive correlation with NAO and negative correlation with SOI. To summarize, negative NAO, PDO and EAWR events tend to increase TXx and GSL and decrease TNn in Gansu Province, while positive SOI tends to increase TXx and GSL but decrease TNn.
Previous studies have shown that positive SOI coincides with abnormally cold ocean water across the eastern tropical Pacific typical of La Niña episodes, which brings China a cooler winter and hotter spring and summer (CMA 2016). This explains the occurrence of higher TXx, lower TNn and longer GSL under positive SOI phase. Li and Zhang (2015) found connections between the surface air temperature anomalies in Northwest China and the different development phases of the NAO. The results suggest that the Ural highs tend to be strengthened during the negative phase of NAO (NAO-) to Atlantic ridge transition and a cyclonic circulation anomaly is distinctly enhanced over the Urals during the positive phase of NAO, which influences surface air temperature over Northwest China. Chen et al. (2013) investigated interannual variability for both extreme low and high temperature and found that these are closely related to ENSO, while interdecadal variability and trend of extreme temperature are obviously associated with the PDO in North China. The results in this study verify the connections between temperature and large-scale circulation found in previous studies and also contribute with information about the spatial distribution of associations in the Gansu Province.

Figure 8 presents the heterogeneous correlation of precipitation extremes, and Table 3 presents the corresponding 


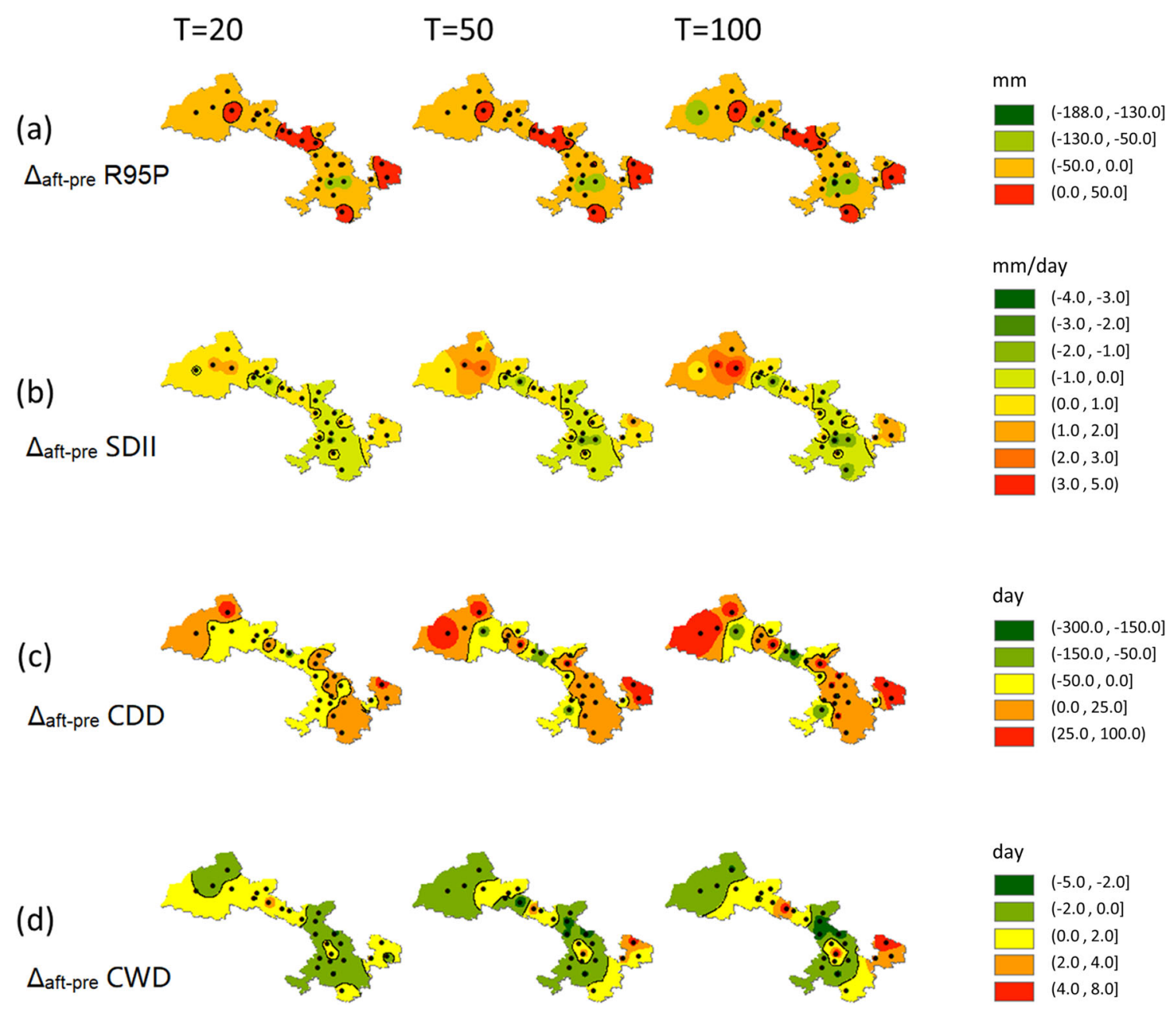

Fig. 6 Spatial distribution of return level difference between aftshift and preshift period of extreme precipitation indices: a $\Delta_{\text {aft-pre }}$ R5P, b $\Delta_{\text {aft-pre }}$ SDII, c $\Delta_{\text {aft-pre }} \mathrm{CDD}$ and $\mathbf{d} \Delta_{\text {aft-pre }} \mathrm{CWD}$ for $T=20,50$ and 100 years; solid black line denotes zero

heterogeneous correlation between climate indices and the first and second modes of SVD with explained variance. NAO, PDO and EAWR have the same influence on the R95P, SDII and CDD for the first mode, while SOI acts with an inverse relationship. Under positive NAO/PDO/EAWR phase or negative SOI phase, R95P and SDII for both northern and southern parts of Gansu tend to decrease, while SDII in the middle part increases. Shorter CDD in the southern part and longer CDD in the north tend to occur under these circumstances. For the first mode, CWD only shows significant correlation with SOI and PDO for stations in the southern part, where an increase of CWD tends to occur under a positive SOI or a negative PDO phase. For the second mode, NAO, PDO and SOI show different influence on R95P and SDII in southern and northern parts of Gansu: positive NAO/PDO or negative SOI, R95P and SDII in the southern part tend to decrease and increase in the northern part. For the second mode, negative SOI/EAWR or positive PDO tends to decrease the length of CDD in most parts of Gansu.
It has been long recognized that large-scale circulation exerts an important impact on the East Asian monsoon, hence influencing the precipitation in China. Yuan et al. (2016b) examined the summer precipitation in the source region of Yellow River, which is close to Gansu, and found teleconnections with global sea surface temperature. Higher sea surface temperature in equatorial Pacific areas corresponding to El Niño coincides with less summer precipitation. Ouyang et al. (2014) found that precipitation in the North China Plain is less during the warm PDO phase and more plentiful during the cool phase. The reason is that precipitation here is always dominated by high pressure and results in precipitation decrease when the Pacific is warm, with the sea temperature over the tropical mid-eastern Pacific rising and that over the central part of northern Pacific is lower than normal. Fu et al. (2008) showed that during a warm PDO phase, the precipitation is less than normal in most parts of China, especially in northern China. Tan and Shao (2017) revealed that EAWR pattern is the most significant large-scale climate pattern that influences wet season precipitation of Xinjiang. 
(a) Mode 1: TXx

$(0.00,0.10]$
$(0.10,0.20]$
$(0.20,0.30]$
$(0.30,0.40]$
$(0.40,0.50]$

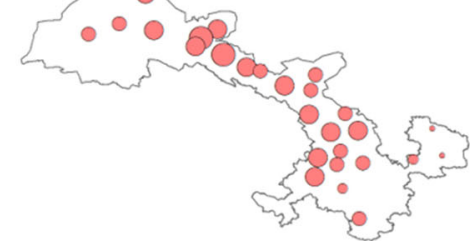

(b) Mode 1: TNn

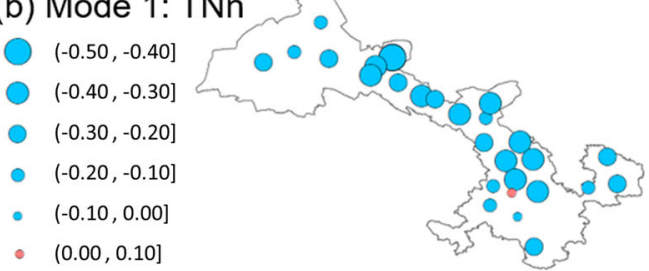

(c) Mode 1: GSL

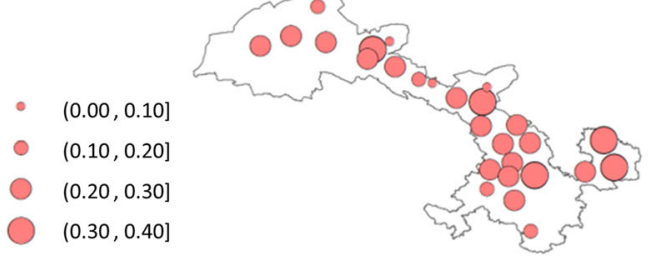

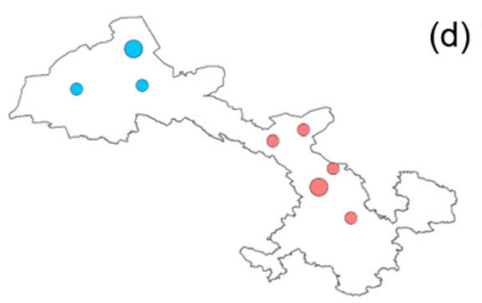

(d) Mode 2: TXx

$(-0.30,-0.20]$

- $(-0.20,-0.10]$

- $(-0.10,0.00]$

- $\quad(0.10,0.20]$

- $(0.20,0.30]$

(e) Mode 2: TNn

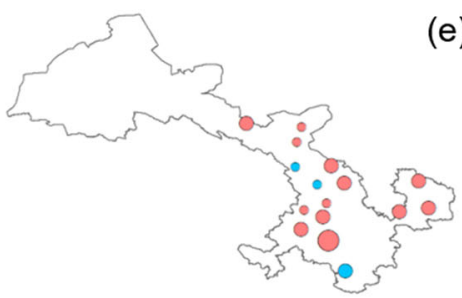

- $(-0.20,-0.10]$

- $(-0.10,0.00]$

- $(0.00,0.10]$

$(0.10,0.20]$

$(0.20,0.30]$

(f) Mode 2: GSL

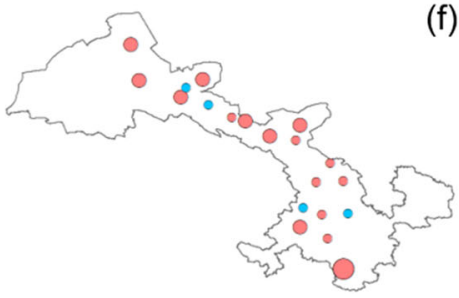

- $(-0.10,0.00]$

- $(0.00,0.10]$

- $(0.10,0.20]$

- $(0.20,0.30]$

Fig. 7 Spatial distribution of heterogeneous correlation from SVD for temperature extremes (only statistically significant correlation at the 0.05 level is shown): a-c mode 1 for Txx, TNn and GSL and $\mathbf{d}-\mathbf{f}$ mode 2 for Txx, TNn and GSL

Because of the unique location of Gansu Province in the middle of Eurasia, the western Pacific monsoon and the westerly from Mediterranean Sea, Black Sea and the North Atlantic interact and influence the precipitation in Gansu Province therefore forming a complex pattern of precipitation extremes. Wang and Zhou (2005) noticed a strengthening trend of the continental high over Eurasia and a weakening trend of

Table 2 Heterogeneous correlation for climate indices (only statistically significant results at the 0.05 level results are shown). Expvar denotes explained variance

\begin{tabular}{llllll}
\hline & NAO & SOI & PDO & EAWR & Expvar (\%) \\
\hline TXx & & & & & \\
Mode 1 & -0.108 & 0.193 & -0.278 & -0.373 & 59.9 \\
Mode 2 & & 0.246 & -0.298 & 0.371 & 18.4 \\
TNn & & & & & \\
Mode 1 & -0.22 & 0.233 & -0.355 & -0.073 & 58.0 \\
Mode 2 & -0.14 & & 0.153 & -0.391 & 20.0 \\
GSL & & & & & \\
Mode 1 & -0.093 & -0.035 & -0.247 & -0.251 & 43.5 \\
Mode 2 & 0.495 & -0.209 & & & 23.4 \\
\hline
\end{tabular}

the western Pacific subtropical high. The north-eastern wind over central-east China is weakening the south-westerly summer monsoon in the region, limiting the northward extension of the summer monsoon and causing a shorter rainy season in north China. They showed that the extreme precipitation events in summer consistently decrease in north China. However, Xu et al. $(2008,2010)$ found that the water vapour transport by the mid-high latitude westerly flows is getting stronger resulting in an increasing rainfall trend, as well as extreme precipitation, in Northwest China.

\section{Conclusion}

In this study, seven temperature and precipitation extreme indices were analysed related to the period 1961-2017 and using data from 27 meteorological stations in Gansu Province, China. The magnitude and frequency of these extreme indices were compared considering the distinct climate shift that occurred in the late 1970s in China. The results indicate possible influence from topography, vegetation cover and south-easterly monsoon flow on spatiotemporal variability of temperature and 
Fig. 8 Spatial distribution of heterogeneous correlation from SVD for precipitation extremes (only statistically significant correlation at the 0.05 level is shown): a-d mode 1 for R95P, SDII, CDD and CWD and $\mathbf{e}-\mathbf{h}$ mode 2 for R95P, SDII, CDD and CWD

(a) Mode 1: R95P
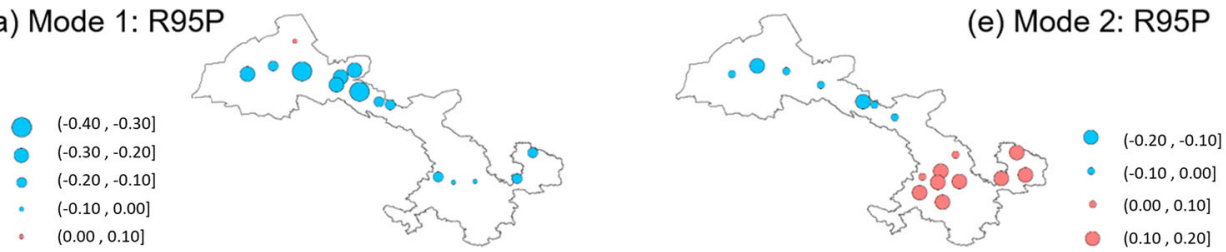

(b) Mode 1: SDII
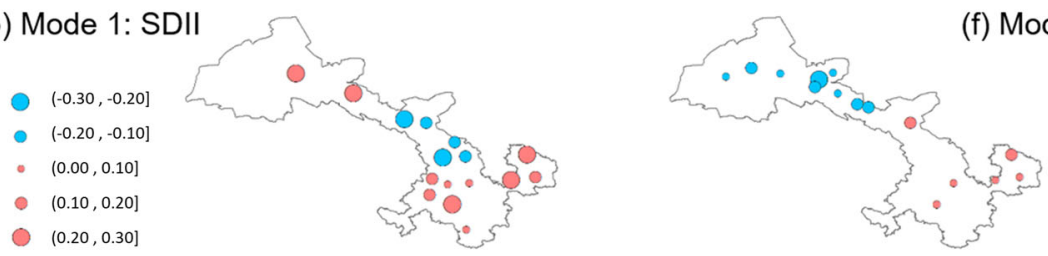

(f) Mode 2: SDII

(c)

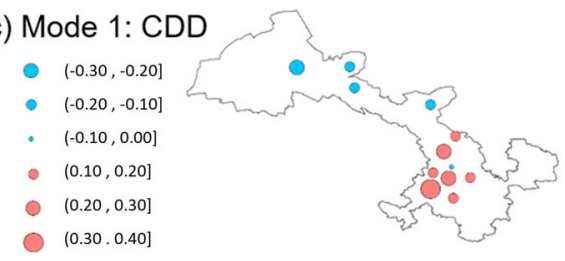

(d)

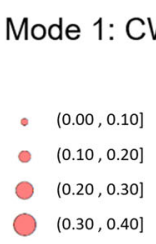

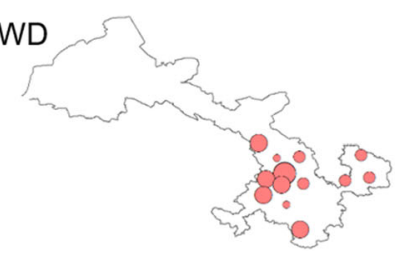

(g) Mode 2: CDD

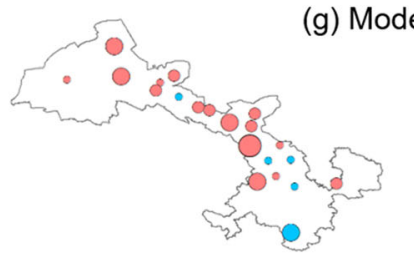

- $\quad(-0.30,-0.20]$

- $(-0.20,-0.10]$

- $(-0.10,0.00]$

$(0.00,0.10]$

$(0.10,0.20]$

$(0.20,0.30]$

$(0.30,0.40]$

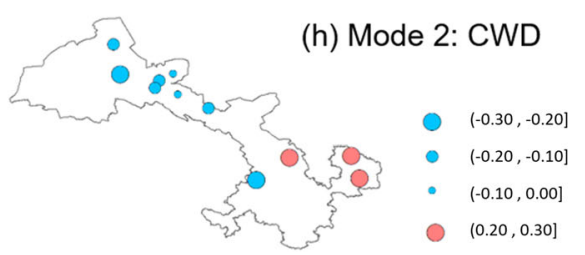

Table 3 Heterogeneous correlation of climate indices (only statistically significant values at the 0.05 level are shown). Expvar denotes explained variance

\begin{tabular}{llllll}
\hline & NAO & SOI & PDO & EAWR & Expvar (\%) \\
\hline R95P & & & & & \\
Mode 1 & 0.097 & -0.078 & 0.118 & 0.515 & 41.7 \\
Mode 2 & -0.166 & 0.255 & -0.25 & & 24.9 \\
SDII & & & & & \\
Mode 1 & -0.204 & 0.288 & -0.234 & -0.511 & 44.5 \\
Mode 2 & -0.309 & 0.065 & -0.146 & 0.227 & 24.7 \\
CDD & & & & & \\
Mode 1 & -0.514 & 0.219 & -0.274 & -0.195 & 36.0 \\
Mode 2 & & 0.21 & -0.22 & 0.376 & 30.1 \\
CWD & & & & & \\
Mode 1 & & 0.571 & -0.222 & & 39.0 \\
Mode 2 & & & & 0.481 & 24.6 \\
\hline
\end{tabular}

precipitation extremes. An increase in temperature extremes both regarding magnitude and frequency for the aftshift as compared with the preshift period was revealed, suggesting warmer conditions in recent years. Precipitation extremes had different response depending on location in the Gansu area, but in general indicated a less extreme precipitation pattern in southern Gansu, however, a potential strengthening trend of precipitation extremes in the north.

Another major finding of this study was to identify the influence of large-scale circulation, which can be used to predict future patterns of temperature and precipitation extremes in this area. The results showed that temperature and precipitation extremes are closely related to NAO, SOI, PDO and EAWR. The strengthening of westerlies and weakening of the south summer monsoon jointly contribute to the complex spatiotemporal pattern of precipitation extremes. As the future phases of large-scale circulation patterns are possible to be estimated based on ensemble global climate models (GCMs) 
and empirical linear inverse modelling, they provide us possibilities to predict future patterns of extreme temperature and precipitation. At the same time, given the relative uncertainty in future large-scale circulation phases, hypotheses on future climate patterns need to be verified and confirmed with numerical models.

There are obvious needs to improve the understanding of local climate variability with joint influence from large-scale circulation. Further analyses of wind, pressure and moisture transport should be included to enrich the interpretation. Other factors including land surface processes and anthropogenic effects are as well important (Peng et al. 2013).

Acknowledgements We acknowledge China Meteorological Administration (CMA) and National Oceanic and Atmospheric Administration of United States (NOAA) for providing data in conducting the analysis in this paper. This work was supported by the Chinese national key research project (No. 2018YFC1508001).

Funding Information Open access funding provided by Lund University.

\section{Compliance with ethical standards}

Conflict of interest The authors declare that they have no conflict of interest.

Open Access This article is distributed under the terms of the Creative Commons Attribution 4.0 International License (http:// creativecommons.org/licenses/by/4.0/), which permits unrestricted use, distribution, and reproduction in any medium, provided you give appropriate credit to the original author(s) and the source, provide a link to the Creative Commons license, and indicate if changes were made.

\section{References}

Allan RP, Soden BJ (2008) Atmospheric warming and the amplification of precipitation extremes. Science 321:1481-1484

Barnston AG, Livezey RE (1987) Classification, seasonality and persistence of low-frequency atmospheric circulation patterns. Mon Weather Rev 115:1083-1126

Bretherton CS, Smith C, Wallace JM (1992) An intercomparison of methods for finding coupled patterns in climate data. J Clim 5:541-560

Casanueva A, Rodriguez-Puebla C, Frias MD, Gonzalez-Reviriego N (2014) Variability of extreme precipitation over Europe and its relationships with teleconnection patterns. Hydrol Earth Syst Sci 18: 709-725

Chen XY, Zhu YM, Xia LL, Zhang WX (2013) Analysis of extreme temperature events in North China based on EMD method. Appl Mech Mater 295-298:854-858

Chen Y, Li Z, Fan Y, Wang H, Deng H (2015) Progress and prospects of climate change impacts on hydrology in the arid region of northwest China. Environ Res 139:11-19

Cheng QY, Gao XQ, Lin S, Zhao HY, Yang SH (2017) Drought characteristics analysis of Gansu in recent 50 years based on meteorological drought composite index. Agric Res Arid Areas 35:211-218

CMA. 2016. China Meteorological Administration Report. http://data. cma.cn/site/article/id/28912.html. ().
Cudennec C, Leduc C, Koutsoyiannis D (2007) Dryland hydrology in Mediterranean regions - a review. Hydrol Sci J 52:1077-1087

De Michele C, Avanzi F (2018) Superstatistical distribution of daily precipitation extremes: A worldwide assessment. Sci Rep 8:14204-14204

Diaz HF, Grosjean M, Graumlich L (2003) Climate variability and change in high elevation regions: past, present and future. Clim Chang 59:1-4

Feng S, Nadarajah S, Hu, Q. (2007) Modeling annual extreme precipitation in China using the generalized extreme value distribution. Journal of the Meteor Soc of Japan Ser II 85:599-613

Fu C, Jiang Z, Guan Z, He J, Xu Z-F (2008) Regional climate studies of China. Springer Sci \& Bus Media:105-110

Gao T, Xie L (2016) Spatiotemporal changes in precipitation extremes over Yangtze River basin, China, considering the rainfall shift in the late 1970s. Glob Planet Chang 147:106-124

Gong DY, Ho, C. H. (2002) Shift in the summer rainfall over the Yangtze River valley in the late 1970s. Geophys Res Lett 29:78-1-78-4

Graham NE (1994) Decadal-scale climate variability in the tropical and North Pacific during the 1970s and 1980s: observations and model results. Clim Dyn 10:135-162

Guan Q, Yang L, Guan W, Wang F, Liu Z, Xu, C. (2018) Assessing vegetation response to climatic variations and human activities: spatiotemporal NDVI variations in the Hexi Corridor and surrounding areas from 2000 to 2010. Theor Appl Climatol

$\mathrm{Hu}$ Q, Tawaye Y, Feng S (2004) Variations of the northern hemisphere atmospheric energetics: 1948-2000. J Clim 17:1975-1986

Jenkinson AF (1969) Estimation of maximum floods. World Meteoro Org Tech Note 98:183-227

Jia WX (2016) Temporal and spatial variations in extreme temperatures in the Qilian Mountains-Hexi Corridor over the period 1960-2013. $J$ Mt Sci 13:2224-2236

Karl TR, Easterling DR (1999) Climate extremes: selected review and future research directions. In: Karl TR, Nicholls N, Ghazi A (eds) Weather and Climate Extremes: Changes, Variations and a Perspective from the Insurance Industry. Springer Netherlands, Dordrecht

Karl TR, Nicholls N, Ghazi A (1999) CLIVAR/GCOS/WMO workshop on indices and indicators for climate extremes - workshop summary. Clim Chang 42:3-7

Li B, Chen Y, Shi X, Chen Z, Li W (2013) Temperature and precipitation changes in different environments in the arid region of northwest China. Theor Appl Climatol 112:589-596

Li C, Wang R (2017) Recent changes of precipitation in Gansu, Northwest China: An index-based analysis. Theor Appl Climatol 129:397-412

Li C, Zhang Q (2015) An observed connection between wintertime temperature anomalies over Northwest China and weather regime transitions in North Atlantic. Jour of Meteoro Res 29:201-213

Ouyang R, Liu W, Fu G, Liu C, Hu L, Wang H (2014) Linkages between ENSO/PDO signals and precipitation, streamflow in China during the last 100 years. Hydrol Earth Syst Sci 18:3651-3661

Peel MC, Finlayson BL, MCMahon TA (2007) Updated world map of the Köppen-Geiger climate classification. Hydrol Earth Syst Sci 11: $1633-1644$

Peterson TC, Folland C, Gruza G, Hogg W, Mokssit A (2001) Report on the activities of the working group on climate change detection and related Rapporteurs 1998-2001. (Available as: wgccd.2001.pdf). In: World Meteorological Organization, Geneva, Rep. WCDMP-47, WMO-TD 1071143 pp

Redmond KT, Koch RW (1991) Surface climate and streamflow variability in the Western United States and their relationship to large-scale circulation indices. Water Resour Res 27:2381-2399

Tan X, Shao D (2017) Precipitation trends and teleconnections identified using quantile regressions over Xinjiang, China. Int J Climatol 37: $1510-1525$ 
Tu K, Yan Z, Dong W (2010) Climatic Jumps in Precipitation and Extremes in Drying North China during 1954-2006. Journal of the Meteor Soc of Japan Ser II 88:29-42

Uvo CB, Repelli CA, Zebiak SE, Kushnir Y (1998) The relationships between tropical Pacific and Atlantic SST and Northeast Brazil monthly precipitation. J Clim 11:551-562

Wallace JM, Smith C, Bretherton CS (1992) Singular value decomposition of wintertime sea surface temperature and $500-\mathrm{mb}$ height anomalies. J Clim 5:561-576

Wang H, Zhang Q, Wang R, Lv X, Wang L, Zhang L, Qi Y (2017a) Effects of climate change on agro climatic resources and potential primary cropping patterns in Gansu Province. (in Chinese with English abstract). Acta Ecol Sin 37:6099-6110

Wang Y, Zhang Q, Wang SP, Wang JS, Yao YB (2017b) Characteristics of agro-meteorological disasters and their risk in Gansu Province against the background of climate change. Nat Hazards 89:899-921

Wang Y, Zhou L (2005) Observed trends in extreme precipitation events in China during 1961-2001 and the associated changes in largescale circulation. Geophys Res Lett 32

Washington R, Hodson A, Isaksson E, MacDonald O (2000) Northern Hemisphere teleconnection indices and the mass balance of Svalbard glaciers. Int J Climatol 20:473-487

Wen X, Wu X, Gao M (2017) Spatiotemporal variability of temperature and precipitation in Gansu Province (Northwest China) during 1951-2015. Atmos Res 197:132-149
Xiao M, Zhang Q, Singh VP (2015) Influences of ENSO, NAO, IOD and PDO on seasonal precipitation regimes in the Yangtze River basin, China. Int J Climatol 35:3556-3567

Yuan F, Berndtsson R, Uvo CB, Zhang L, Jiang P (2016a) Summer precipitation prediction in the source region of the Yellow River using climate indices. Hydrol Res 47:847-856

Yuan F, Yasuda H, Berndtsson R, Bertacchi U, VO C, Zhang L, Hao Z, WANG, X. (2016b) Regional sea-surface temperatures explain spatial and temporal variation of summer precipitation in the source region of the Yellow River. Hydrol Sci J 61:1383-1394

Yuan Y, Yang H, Zhou W, Li, C. (2008) Influences of the Indian Ocean dipole on the Asian summer monsoon in the following year. Int $J$ Climatol 28:1849-1859

Zhai P, Zhang X, Wan H, Pan X (2005) Trends in total precipitation and frequency of daily precipitation extremes over China. J Clim 18: 1096-1108

Zhang, X. \& Yang, F. 2004. RClimDex 1.1. http://etccdi.pacificclimate. org/software.shtml. (Accessed April 9th, 2018).

Zhou B, Xu Y, Wu J, Dong S, Shi Y (2016) Changes in temperature and precipitation extreme indices over China: analysis of a highresolution grid dataset. Int J Climatol 36:1051-1066

Publisher's note Springer Nature remains neutral with regard to jurisdictional claims in published maps and institutional affiliations. 